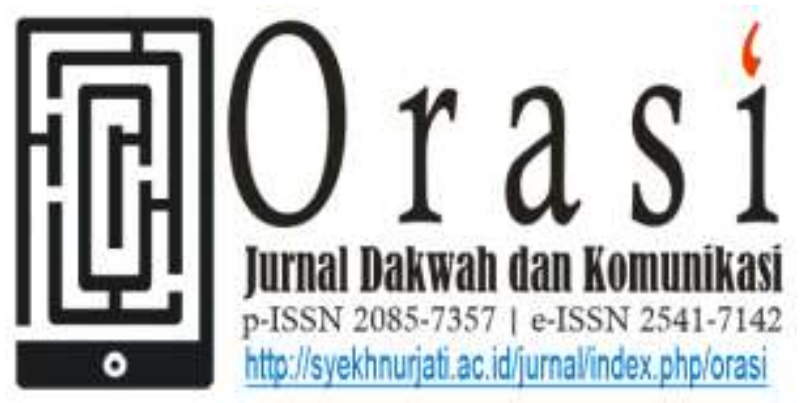

Volume 11 No. 1 Juli 2020

\title{
TREN BUDAYA INDUSTRI PADA LAGU DIDI KEMPOT: PERSPEKTIF TEORI KRITIS
}

\section{TREND OF THE CULTURE INDUSTRY ON DIDI KEMPOT'S SONG: A CRITICAL THEORY PERSPECTIVE}

\author{
Bayujati Prakoso \\ Program Studi Magister Ilmu Komunikasi, Fakultas Ilmu Sosial dan Ilmu Politik, Universitas Diponegoro \\ e-mail: bayujatiprakoso@students.undip.ac.id
}

\begin{abstract}
ABSTRAK
Penelitian ini membahas fenomena tren budaya industri, yakni musik yang berkembang di Indonesia. Tujuan dalam penelitian ini yaitu untuk memahami tren Lagu Didi Kempot dalam tinjauan Teori Kritis. Penelitian ini menggunakan Teori Kritis mazhab Frankfurt, pendekatan kualitatif-deskriptif. Hasil penelitian menunjukkan bahwa; Pertama, lagu Didi Kempot diterima sebagai wujud kesenangan diri dan ekspresi hati bagi milenial tanpa perlu dimaknai secara eksplisit makna (asli) lagunya, dan tidak ada keserasian makna lirik Cendol Dawet dengan makna lagu Didi Kempot. Kedua, tren Didi Kempot muncul dengan penambahan lirik Cendol Dawet dan aransemen Jawa Koplo, dan publikasi melalui akun Instagram \& YouTube Didi Kempot, serta akun komunitas Sobat Ambyar Indonesia. Dalam kondisi ini, terdapat komodifikasi konten lagu Didi Kempot ditambah lirik Cendol Dawet yang ditampilkan melalui YouTube dengan monetisasi, barang dagangan serba Didi Kempot, dan juga banyaknya agenda konser eksklusif Didi Kempot seperti konser yang ada dalam program Televisi, konser-konser, maupun dari event organizer. Maka, secara tidak sadar, masyarakat dikontrol, seolah tidak memiliki otonomi untuk memilih (industri budaya lainnya) karena sudah menjadi kebahagiaan kolektif (kebutuhan palsu).
\end{abstract}

Kata Kunci: Budaya Industri, Didi Kempot, Kebutuhan Palsu, Komodifikasi Konten, Teori Kritis Mazhab Frankfurt

ABSTRACT

This research discusses the phenomenon of industrial culture trend in music developing in Indonesia. It aimed to understand Didi Kempot's song trends in Critical Theory perspective. This research used The Frankfurt School's critical theory, applying a qualitative-descriptive approach. The results show that: first, 
Didi Kempot's song was accepted as a form of self-indulgence and heart expression for the millennials without the original meaning of the song being interpreted explicitly, and there was actually no connection between the phrase Cendol Dawet with the meaning of Didi Kempot's song; and second, Didi Kempot's trend emerged because of the addition of Cendol Dawet to the lyrics and Javanese Koplo music arrangement, the publication through Didi Kempot's Instagram and YouTube accounts, and the Indonesian Sobat Ambyar community. In this case, there was commodification of Didi Kempot's song added with the lyric of Cendol Dawet displayed through the YouTube channel with monetization, Didi Kempot's merchandise, as well as the many exclusive Didi Kempot's concert agendas such as concerts on television programs, off-air concerts, or from the event organizer. Thus, unconsciously, the community was being controlled as if they did not have the autonomy to choose (other cultural industries) because it had become a collective happiness (false needs).

Keywords: Commodification of Content, Didi Kempot, False Needs, Frankfurt School's of Critical Theory, Industrial Culture

\section{Pendahuluan}

Dinamika kajian budaya nampaknya membawa pengaruh penting dalam memahami sebuah kebudayaan. Budaya tersebut dapat dimaknai tidak sebatas sebagai sesuatu yang diproduksi turun-temurun, melainkan sebuah bersifat situasional yang keberadaannya bergantung kepada karakter kekuasaan dan hubungan yang berubah dari masa ke masa secara kontekstual. Hal ini juga didalamnya terdapat nilai budaya yang terus berkembang — budaya populer.

Popular Culture atau sering disebut budaya populer/pop mulai marak di Indonesia. Tidak dapat dipungkiri, perkembangan budaya pop sejauh ini nampak bahwa media sebagai alat penyebarannya. Praksis ini, menurut Sedyawati dalam (Arybowo 2010) memungkinkan untuk mewujudkan suatu nilai ekonomis - dapat terjadi secara langsung karena unsur itu terkandung di dalam hasil “industri budaya" yang diperdagangkan. Dari proses tersebut, seacara implisit melalui penciptaan sistem semacam ilusi yang mengikat masyarakat.

Dalam kerangka demikian, bahasa menjadi penting untuk dicermati. Bahasa, dalam konteks budaya populer tidaklah bersifat objektif dan independen. Bahasa, tidak menjadi tempat yang netral, bahkan cenderung subjektif (beragam makna) berdasarkan hasil konstruksinya. Hal ini menjadikan bahasa diproduksi, bahkan direproduksi sebagai sesuatu yang baru, dan tergantung konteks fungsi pragmatisnya. Bahasa, dan media menjadi hal yang tak terpisahkan sebagai suatu entitas formulasi baru dalam menciptakan budaya populer di era pasca modern.

$\begin{array}{rrrr}\text { Media sebagai industri } & \text { budaya } \\ \text { memiliki keterkaitan dengan upaya }\end{array}$
komodifikasi. Media menjadi instrumen budaya popular itu tercipta dan berkembang. Media memiliki letak yang strategis sebagai instrumen dalam rangka menyebarluaskan budaya populer. Sementara, tanpa disadari 
pesan yang ada dalam media mempengaruhi keinginan konsumen dan budaya tradisional.

$$
\text { Hasil penelitian Ulya }
$$
menunjukkan adanya bentuk komodifikasi pekerja, yakni para YouTuber yang proses tersebut, secara tidak sadar berjalan ketika menjadi YouTuber. YouTube memiliki konten sepenuhnya, sehingga upaya mengendalikan upah (monetisasi) bagi YouTuber diatur oleh standar yang dimiliki oleh YouTube. Saat media komersial mencapai pemirsanya di masyarakat, tanpa disadari masyarakat, pesan yang ada dalam media, kemudian mempengaruhi keinginan konsumen dan budaya tradisional mereka, dan tanpa disadari pula akan meningkatkan keuntungan pembuatnya. (Arviani 2013) Pada titik ini, peningkatan ekonomi bagi industri musik berpotensi begitu besar melalui rekaman, komposisi, maupun pertunjukan musiknya (Khadavi 2014).

Ihwal fenomena tren lagu Didi Kempot menjadi begitu populer di Indonesia. Pada sekitar bulan Juni 2019, Didi Kempot, penyanyi yang ber-genre Campur Sari yang berasal dari Solo, Jawa Tengah ini mencoba menyanyikan lagu-lagu ciptaannya dengan berbahasa Jawa. Fenomena lagu-lagu Didi Kempot ini bermula ketika sebuah video yang diunggah oleh akun twitter Agus Magelang @ AgusMagelangan menjadi viral. Sosok Agus inilah yang kemudian memberi julukan The Godfather of Broken Heart kepada Didi Kempot. Video tersebut menampilkan sekelompok anak muda yang begitu menghayati lagu-lagu yang dibawakan Didi Kempot. Video itu diunggah kembali oleh akun Instagram@sobatambyar pada 12 Juni 2019 (Kompas 2019). Perkembangan budaya populer diatas tidak bisa di pisahkan dari media sosial seiring dengan kemajuan teknologi. Hal ini dapat dilihat pada akun media sosial resmi Didi Kempot saat ini:
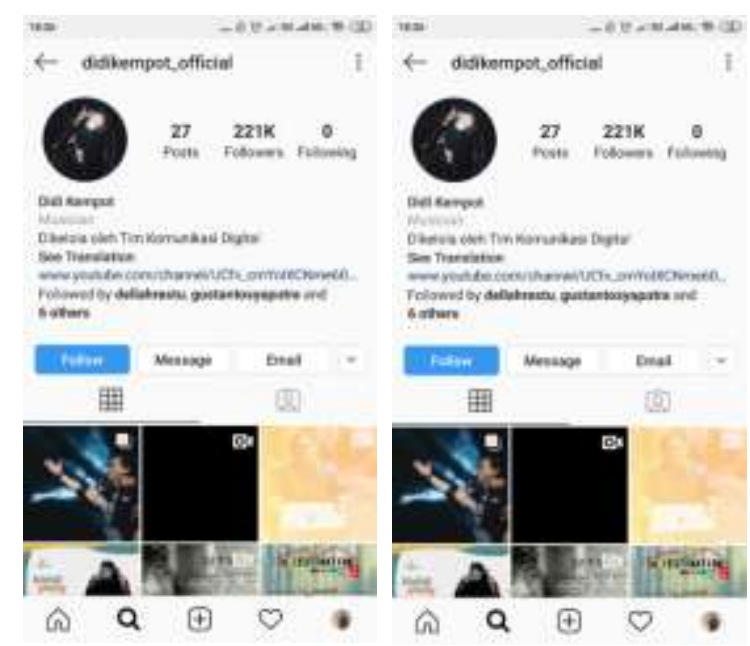

Gambar 1. Media Sosial Instagram \& YouTube Resmi Didi Kempot

(Sumber: Instagram.com/Youtube.com)

Dapat dilihat pada gambar diatas bahwa, akun media sosial Didi Kempot, di Instagram sudah mencapai followers yang berjumlah 156 ribu pengguna, sementara dalam akun YouTube-nya mencapai 515 ribu subscriber dengan prosentase tertinggi jumlah views mencapai sekitar 10 juta penonton. Hal ini menandakan bahwa peminat Didi Kempot sungguh luar biasa banyak. Ketika penulis telusuri komentar, dan jumlah views dari kedua akun media sosial tersebut publik begitu berkeinginan secara emosional, psikologis untuk mendengarkan secara langsung atau tidak langsung melalui media sosial. Mengekspresikan luapan beragam perasaan ini seperti yang tergambar pada bentuk komentar publik di akun media sosial Didi Kempot, sebagai berikut: 


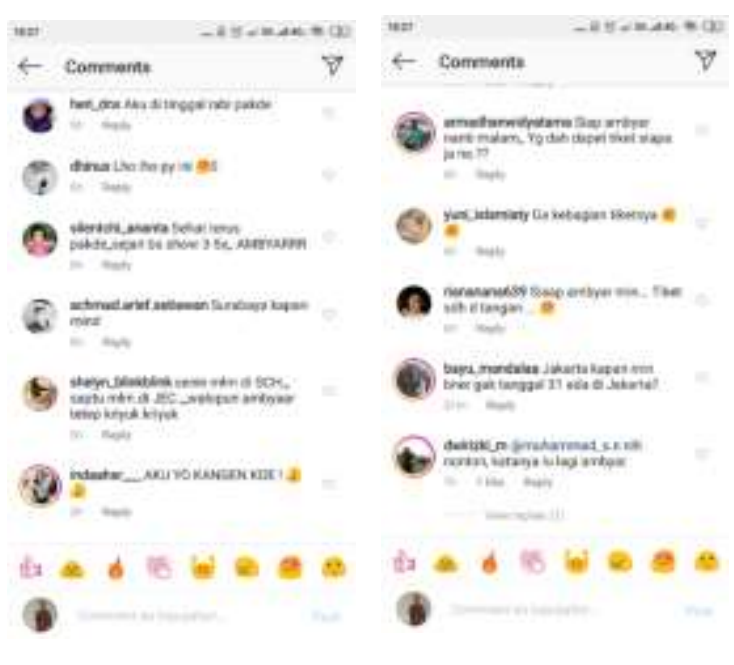

Gambar 2. Komentar-komentar khalayak di akun media sosial Instagram resmi Didi Kempot

(Sumber: Instagram.com)

Pop culture yang lagi marak atau trending topik saat ini adalah lagu Didi Kempot yang dalam liriknya terdapat kalimat "Cendol Dawet". Kemunculan pop culture seperti yang telah disebutkan diatas mendapatkan perhatian dan sambutan yang luar biasa dari seluruh elemen masyarakat di berbagai kalangan dari anak kecil, remaja, hingga orang dewasa. Lagu ciptaannya yang kini sangat populer berjudul: Banyu Langit, Cidro, Layang Kangen, Pamer Bojo, Sewu Kutho. Berdasar pengamatan peneliti, per tanggal 10 Mei 2020, penonton video dalam akun resmi YouTube Didi Kempot telah mencapai 45.245.996 kali ditonton. (https://www.youtube.com/watch?v=20_CyA4 CCTs, diakses pada 10 Mei 2020)

Setiap lagu yang dibawakan Lord Didi (begitu dia dipanggil) selalu memancing emosi penontonnya. Lagu-lagu yang terkesan sedih, seperti ditinggalkan oleh kekasih, sakit hati, dan sebagainya Pada pertengahan lagu "Pamer Bojo," misalnya, mereka serempak mengepalkan tangan ke atas sambil berteriak
"Cendol Dawet! Cendol Dawet! Seger Piro 500an, gapake ketan, Ji, ro, lu, pat, limo, enam, pito wolu" lalu berjoget. Tidak berhenti disitu, mereka pula para penikmat musik Didi Kempot ada menyepakati dengan mengikuti prosesi kenikmatan lagu ini. Hal ini terbukti dengan beberapa penonton naik ke pundak temannya dan terus menggerakkan tangan dan tubuhnya. Ditambah kalimat, "daripada sakit hati mending dijogetin," kata Didi di atas panggung.

Selain itu, dalam setiap konsernya ia menyebut lagu-lagunya selain untuk hiburan, adalah untuk merawat tradisi Jawa, dengan mencintai bahasa Jawa. Menurutnya, bahasa Jawa perlu dilestarikan oleh segenap warga negara Indonesia. Bahasa juga, lanjutnya, adalah salah satu produk bangsa yang tidak boleh hilang. Oleh karena itu, beliau menciptakan dan mempopulerkan lagu bahasa Jawa.

Maka, menarik untuk diteliti, penelitian ini ingin menganalisis bagaimana tren budaya industri yang berkembang di Indonesia yaitu lagu Didi Kempot dengan tinjauan Teori Kritis mazhab Frankfurt School.

\section{Metodologi Penelitian}

Metode dalam penelitian ini adalah menggunakan kualitatif. Pendekatan kualitatif bertujuan untuk membantu peneliti memahami bagaimana perasaan orang dan mengapa mereka merasakannya. Hal ini mensyaratkan pada pengumpulan informasi secara mendalam (in-depth information) untuk menjawab pertanyaan penelitian seperti bagaimana (how), dan mengapa (why) (Bhojanna 2012). 
Jenis penelitian yang digunakan adalah penelitian deskriptif, yang bertujuan untuk memberikan gambaran detail spesifik terkait dengan situasi, latar sosial, atau hubungan (Neuman 2014).

Kemudian, sumber data yang digunakan adalah studi pustaka (primer), dan wawancara tidak terstruktur sebagai data sekundernya.

\section{Hasil dan Pembahasan}

\subsection{Hasil Analisis}

Didi Kempot sempat menjadi trending topic Twitter pada hari Senin (10/6/2019) pagi seperti dilansir Tribunnews.com, yakni Didi Kempot meraih 2800k-an tweets.

\section{Indonesia trends. "Senin \\ "WELCOMEHOMEROSÉ 52.8K Tweets \\ "DGITM \\ Didi Kempot \\ 2,809 Tweets \\ Cyberpunk 2077 \\ 74.4K Tweets \\ "BubarkanFPI \\ 1,559 Tweets \\ Portugal \\ 371K Tweets}

Gambar 3. Trending Topic Didi Kempot. (Sumber: https://www.tribunnews.com, diakses pada 25 November 2019)

Kompas dalam ulasannya yang berjudul "Sobat Ambyar dan Sihir Didi Kempot" mencoba mengulas mengapa sampai ramai dan sangat populer lagu Didi Kempot ini. Salah satunya melalui wawancara yang dilakukan kepada masyarakat, sebagai berikut:

Menurut Ayu (25), lagu Didi Kempot begitu relevan dan sering dialami oleh anak muda segala zaman, patah hati, misalnya. Sementara, Rizky (23) menuturkan bahwa lirik lagu yang ditambahkan dengan gendang campur sari membuat seolah sihir yang merasuk ke dalam hati dan jiwa penikmat musiknya (pendengar), walau mereka belum memahami arti lagu nya yang berbahasa Jawa. Bahkan, Dian (25) mengakui telah menggunakan aplikasi terjemahan untuk memahami lirik lagu Didi Kempot.

Dalam konteks ini, lagu tersebut dinilai oleh kaum milenial sebagai lagu yang bermuatan patah hati, kangen. Namun, yang menjadi menarik ketika lagu yang bermuatan tujuan tersebut dimaknai dengan lagu sedih, namun tidak harus selalu menderita. Secara tidak langsung, para penonton, penikmat lagu sedih Didi Kempot ini membuat seolah ilusi bahwa lagu sedih itu ditampilkan dengan bahagia dan tidak harus menderita.

Sehingga, dewasa ini, Didi Kempot disebut memiliki julukan dari para penikmat/fansnya dengan sebutan "The Godfather of Broken Heart". Penamaan gelar tersebut diberikan kepada Didi Kempot lantaran lagu-lagu sedih yang diciptakan dan dibawakan olehnya tampil dan dinikmati oleh segenap kalangan di Indonesia.

Alasan lainnya yakni Didi Kempot memiliki gaya nyanyi yang khas dengan penggunaan bahasa Jawa dan lirik yang mendayu-dayu. Dari mulai orang-orang Jawa sendiri (pribumi), sampai orang yang diluar latarbelakang budaya Jawa asli, seperti kaum milenial yang berada di sejumlah tempat seperti di Jabodetabek, Sumatera, dan sebagainya. 
Bahkan, fansnya juga memiliki nama, yaitu "Sobat Ambyar". Komunitas Sobat Ambyar terbentuk melalui sebuah acara yang diadakan Rumah Blogger Indonesia di Solo pada pertengahan Juni 2019. Komunitas ini juga melebarkan informasi mengenai konser Didi Kempot di berbagai daerah di Indonesia; Jakarta, Tangerang, Semarang, Surakarta, Malang, Surabaya, Balikpapan, Yogyakarta, dan lainnya, sekaligus menyapa publik melalui media sosial. Hal ini dapat dilihat akun media sosial Sobat Ambyar berikut ini:

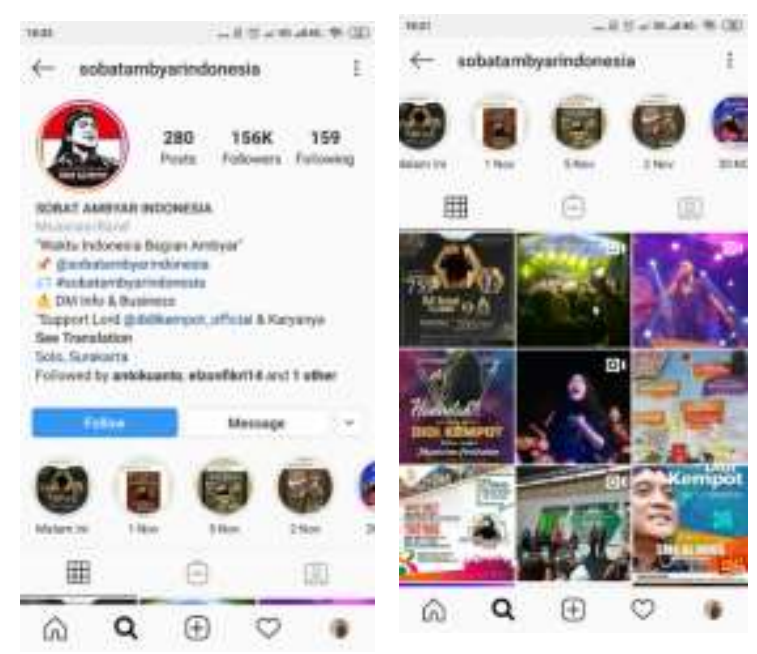

Gambar 4. Akun Media Sosial Komunitas Sobat Ambyar (dikelola tim)

(Sumber: Instagram.com)

Ditambah dengan beberapa publikasi secara besar-besar ketika Didi Kempot diundang oleh beberapa stasiun Televisi, lalu dari undangan konser, reuploader dari publik, maupun tim sobat ambyar, seperti yang dapat dilihat pada gambar 5 .

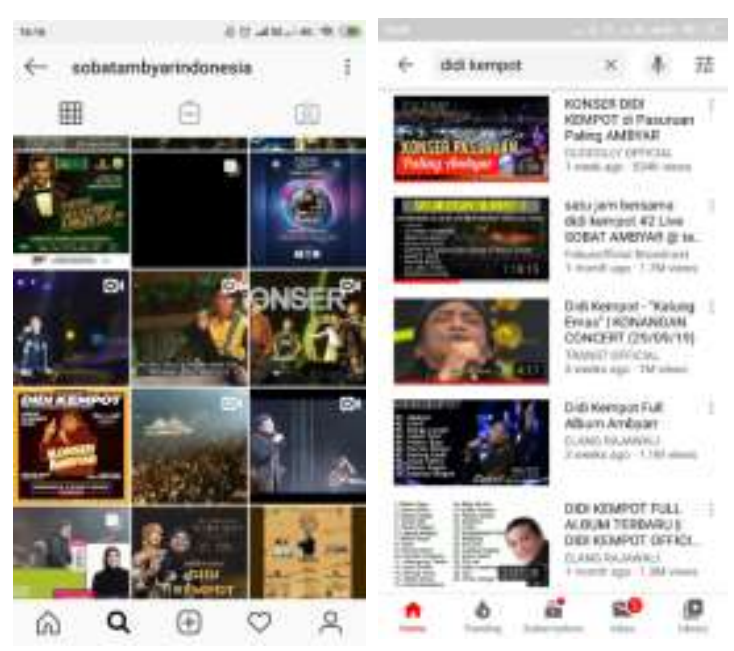

Gambar 5. Aktivitas Publikasi Sobat Ambyar (dikelola tim)

(Sumber: Instagram.com, Youtube.com)

Kemudian, kehadiran Didi Kempot dalam aktivitas konsernya di Sleman City Hall (28/10/2019) dan Konser di Diskotik Babyface Semarang (11/10/2019) (Sumber:

Instagram.com, Youtube.com).

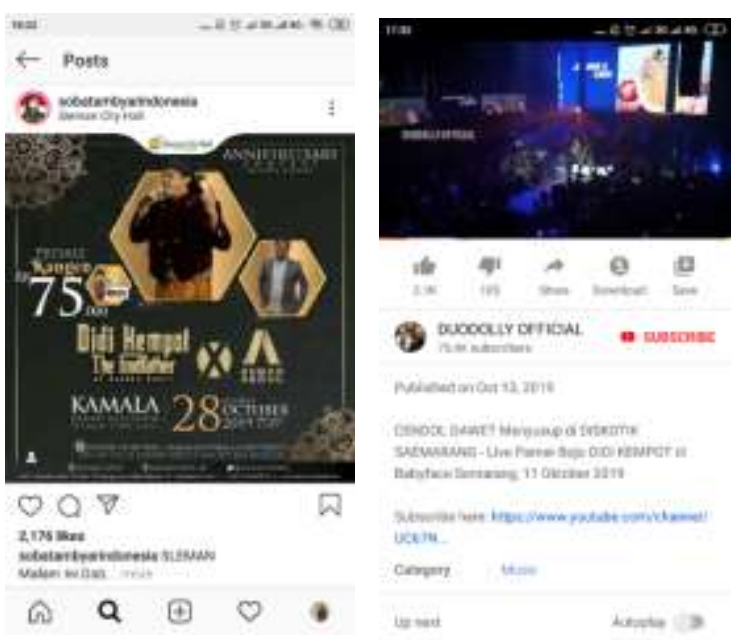

Gambar 6. Aktivitas Konser Didi Kempot di Sleman City Hall (28/10/2019) dan Konser di Diskotik Babyface Semarang (11/10/2019)

(Sumber: Instagram.com, Youtube.com)

Gambar diatas adalah salah satu jadwal konser Didi Kempot di Sleman City Hall yang dilaksanakan pada tanggal 28 Oktober 2019. Menarik untuk diamati bahwa Didi Kempot juga tampil dan memberi nuansa Cendol Dawet dalam lagu Didi Kempot di 
Diskotik. Maka, hal diatas dapat dimaknai bahwa lagu Didi Kempot adalah lagu yang memikat seluruh kalangan. Artinya, lagu yang dibawakan oleh Didi Kempot bernuansa menyentuh beragam lapisan masyarakat, tidak kenal tempat, usia, atau generasi sekalipun.

Sebagaimana pada salah satu lirik lagu "Sewu Kutho": "Sewo kuto uwis tak liwati, Sewu ati tak takoni, Nanging kabeh, podo rangerteni, Lungamu neng endi, Pirang tahun anggonku nggoleki."

Pada lagu diatas dapat dipahami bahwa, tentang seorang kekasih yang pergi dan tidak tahu lagi di mana keberadaan-nya, meski sudah seribu kota dilewati dan seribu orang ditanya keberadaannya, sang kekasih tetap tidak ditemukan. Tatkala, Di hatinya, dia sangat merindukan kekasih itu dan ingin melihatnya walau hanya sebentar saja. Sementara, dalam lirik lagu lainnya, Didi Kempot dengan judul "Cidro" menggambarkan tentang seseorang yang diselingkuhi oleh pasangannya berulang kali sehingga dia merasa tersakiti dan akhirnya memutuskan untuk meninggalkan kekasihnya. Kata "Cidro" sendiri mengandung arti "luka yang mendalam" atau bisa juga berarti “mengingkari janji”.

Selain itu, pada lirik lagu berjudul "Layang Kangen": "Layangmu tak tompo wingi kuwi, Wis tak woco opo karepe atimu, Trenyuh ati iki moco tulisanmu, Ra kroso netes eluh ning pipiku."

Pada lagu diatas menggambarkan tentang kerinduan seseorang kepada kekasihnya yang berada jauh darinya, sehingga dia tidak sabar untuk kembali pulang dan bertemu kekasihnya. sangat digemari para pejuang LDR. Arti dari Layang Kangen sendiri adalah Surat Rindu.

Ernungtyas et al. (2016) meneliti mengenai bagaimana produk fashion bermerek berdampak pada pekerja muda perempuan. Hasilnya menunjukkan bahwa, para pekerja muda perempuan mendapatkan kekuasaan semu ketika menggunakan produk fashion yang bermerek. Disisi lain, terdapat sebuah nilai-nilai sosial yang dipertukarkan terhadap produk fashion bermerek berupa rasa percaya diri, pujian dari orang lain, dan hubungan dengan orang lain.

Dengan contoh diatas, dan menilik hasil riset Ernungtyas et al. (2016) maka, dapat dimaknai bahwa dengan garis besar mengenai Didi Kempot dan lagunya, serta penambahan kalimat Cendol Dawet dan aransemen Jawa Koplo, dan publikasi melalui media baru yang membuat Didi Kempot menjadi tren dan populer ini tidak kemudian hasil cipta budaya merupakan produk murni. Melainkan, hasil produksi kembali dan bekerjasama dengan industri media atau diasumsikan, industri media memanfaatkannya (lagu Didi Kempot dengan aransemen jawa koplo, dan pemanfaatan media tertentu) untuk memperoleh keinginan (hati) masyarakat, sehingga pada satu titik, masyarakat tertarik, keinginan terpenuhi akan kepuasaan pada musik Didi Kempot dan semakin menyukai lagu Didi Kempot. Secara implisit, menjadikan komoditas dan menghasilkan ekonomi yang tinggi bagi produsen tanpa memikirkan refleksi \& makna mendalam dari hasil produk kreatif budaya tersebut. 


\subsection{Tinjauan Teori Kritis Tren Lagu Didi Kempot \& Artistik Cendol Dawet}

Terdapat aliran yang memberikan kritik terhadap modernisme. Aliran ini terbentuk di dalam Institut Penelitian Sosial yang didirikan di Frankfurt, Jerman (1923). Pemikirnya yaitu Theodor W. Adorno, Max Horkheimer, Herbert Marcuse, Friedrich Pollock, Leo Lowenthal, dan Walter Benjamin. Teoretisasi Mazhab Frankfurt (dulu dinamakan Institute for Social Research, dibangun pada tahun 1923) ini mengembangkan teori yang disebut Teori Kritis (Kritische Theorie, Critical Theory) (Agger 2017, Poespowardojo dan Seran 2016).

Teori kritis dari mazhab Frankfurt School ini melakukan kritik atas dasar modernitas dan Marxisme. Sering disebut Neo-Marxisme (kritik atas kapitalisme dan Marxisme). Para penganut neo-Marxist (John Storey 2003, dalam Mariani 2016) menyatakan bahwa terdapat pertentangan yang berpotensi untuk melahirkan revolusi itu tidak terjadi pada level antara buruh dan majikan saja, melainkan terbentuk oleh pusat-pusat (konflik baru) seperti ras, budaya, maupun gender.

Dalam mazhab ini, Poespowardojo dalam pengantarnya menyatakan ciri teori kritis adalah ber-paradigma (Poespowardojo dan Seran 2016) pembebasan, bukan mempertahankan status quo yang bersifat ritual belaka, melainkan efek perubahan dinamis-emansipatoris.

Poespowardojo dan Seran (2016) menguraikan bahwa kritikus modernisme di Institut Penelitian Sosial (IPS) atau dikenal
Mazhab Frankfurt melakukan kritik aliran positivisme (empirisme) logis dan juga kritik pada Marxisme ortodoks dengan cita-cita praksisnya untuk merealisasikan masyarakat berdasarkan pandangan materialisme historis. Kritikus modernisme tersebut menilai bahwa positivism (empirisme) gagal dalam mewujudkan masyarakat modern yang rasional karena pemahamannya tentang ilmu pengetahuan dipersempit menjadi kemampuan teknis. Penilaian tersebut, sama halnya dengan penilaian kritikus modernisme tersebut terhadap Marxisme ortodoks yang gagal merealisasikan masyarakat yang adil. Padahal, pencapaian tujuan utamanya adalah emansipasi.

Horkheimer \& Adorno ingin menunjukkan bahwa apa yang diklaim sebagai kesadaran modern dengan rasio sebagai alat utama dominasi hanyalah akibat dari kehendak manusia untuk berkuasa. Kondisi ini menjelaskan perlunya pencerahan, teori kritis; mampu menganalisis masalah sosial, dan meminggirkan kehendak manusia untuk berkuasa, bukan melalui kesadaran yang mendominasi melalui rasio, namun berupaya membangun semangat pembebasanemansipasi (Poespowardojo dan Seran 2016).

Dalam konteks ini, fungsi pragmatisnya (apa yang dihasilkan) dari sebuah industri budaya ini nampaknya begitu kentara di Indonesia. Industri tersebut semacam membangun kondisi sebagaimana wacana rasionalitas modern yang terlanjur terlalu jauh dan mendalam menciptakan kondisi masyarakat modern yang bersifat semu; kebebasan bersifat semu, dikontrol oleh 
secara tidak sadar oleh masyarakat yang digerakkan modal.

Berkaitan dengan industri budaya ini, Didi Kempot dengan lagu dan artistik lirik Cendol dawet-nya dapat diterima oleh masyarakat, kemudian menjadi sebuah tren budaya industri yang memberikan dampak besar bagi perkembangan budaya, yang memiliki motif membangun semangat cinta budaya Indonesia dengan menyebarluaskan nilai budaya lokal "Jawa" di lagu-lagunya. Namun, secara sekilas tampak seperti hal yang lumrah terjadi dan keharusan sebagai bentuk spirit nasionalisme.

Namun, ketika budaya tersebut mulai masuk (kerjasama) melalui media, dan melakukan pemanfaatan media tersebut, dan berkembang kepada sektor-sektor lain yang menunjang keberlangsung budaya, maka akhirnya menjadi tren. Dalam maksud lain, pemanfaatan media seperti YouTube dengan unggahan video dan monetisasi, membangun komunitas-komunitas di berbagai daerah di Indoensia, serta penjualan merchandise serba Didi Kempot, kemudian diundang dalam konser-konser yang gratis-eksklusif berbayar, hingga diundang dan wawacara di mediamedia nasional.

Maka, dapat dipahami bahwa hal ini terbukti budaya (lagu didi Kempot) menjadi tren industri akhir-akhir ini, sehingga pada akhirnya muncul kesadaran palsu di masyarakat; menciptakan istilah 'ambyar', yakni istilah yang mengungkapkan remuk/hancur hati, sedih dan patah hati dan hal itu menjadi populer dan masyarakat semacam terkena bayangan ilusi tren ini dengan masyarakat beranggapan bahwa "ambyar" itu seringkali ada dalam diri kita, upaya mewakili kesakitan hati dengan lagu Didi Kempot.

Pada kondisi ini, lagu Didi Kempot sebagai wujud representasi diri dan ekspresi kondisi hati yang sedang sedih, gundah, maupun kasmaran. Maka, hal ini semakin memperjelas dan meyakinkan masyarakat untuk selalu menerima dengan menonton, mendengarkan lagu Didi Kempot, menjadi suatu kebiasaan, bahkan memungkinkan menjadi "ritual" kebiasaan sebelum atau sedang melakukan sesuatu sebagai penghibur, penyemangat atau lagu Didi Kempot sebagai wujud bagian kondisi hati masyarakat. Ini merupakan kesadaran palsu ini tidak hanya terjadi sebagai manusia sebagai individu, tetapi juga sebagai masyarakat (Poespowardojo dan Seran 2016).

Tren ini, sebagaimana dijelaskan diatas, terjadi pada informan peneliti yang hendak diwawancarai via media daring WhatsApp, (27/10) Syamsul, mahasiswa di salah satu perguruan tinggi swasta di Jakarta. Ia menyatakan:

"Kalau konser sering kendala sama kegiatan pribadi, jadi gak sering. Kalau dengerin rata rata itu minimal sehari sekali ada lagu didi kempot yang saya dengerin," jelasnya.

Hal tersebut mengisyaratkan dalam lagu Didi Kempot, informan memiliki ketertarikan yang cukup tinggi, dengan mendengarkan lagu Didi Kempot dalam kesehariannya, bahkan ini menjadi kebiasaannya. Ditambah dengan ketika ia mengenal Didi Kempot sejak 2009 di Sragen 
dan hingga kini masih minat dan tertarik dengan lagu Didi Kempot dan memberikan gambaran representasi ekspresi hati dirinya dari lagu Didi Kempot tersebut.

"Karena berkarakter dan
konsisten mas. Bayangkan aja
penyanyi seumuran nya sudah pada
angkat mic Seperti manthous,
koesploes, dll. Tapi didi kempot ini
masih berdiri konsisten," ujar
Syamsul.
"Kalau asli Jawa tulen
mungkin sangat paham makna. Tapi
saya sebagai fans yang gak begitu
mengerti bahasa Jawa lebih jauh sudah
bisa merasakan makna lewat nada dan
ekspresi om didi. Jadi musik2 beliau
ini kadang kalau sudah ngefans itu.
Kita sebagai fans gk harus selalu
memaknai lagu lewat lirik jawanya itu,
tapi juga bisa lewat semacam perasaan
yang terpatri dalam lagu lagu beliau.
Tentu perasaan senang Karena lagu
tradisionalnya, dan sedih melihat
ekspresi dan nada lagunya. Seperti
hancur hati iki," terangnya.

Ia juga menambahkan, bahwa alasan menyukai lagu Didi Kempot adalah karena berkarakter, dan konsisten. Namun, menariknya adalah walaupun dia asli Jawa, ia secara eksplisit menegaskan bahwa fans tidak harus memaknai lagunya dengan alasan lagunya sudah tersemat dalam hati dan bercampur perasaan senang.

Sementara itu, informan kedua, Aninda, mahasiswa di salah satu perguruan tinggi swasta di Jakarta Selatan, generasi milenial asal Sragen yang kini kuliah di Jakarta mengatakan dalam keterangan tertulisnya kepada penulis:

"Suka (lagu Didi Kempot) sejak kecil (TK). Masih suka ya karna terikat oleh budaya yang sama, suara didi kempot yang memang enak dan lirik lagu yang simpel dan lagunya pun menceritakan kejadian sehari-hari yang kita alami," jelas Anin.

"Ada beberapa lagu yg maknanya memang sangat dalam, ya walaupun saya tidak tau seluruh lagulagu didi kempot hehehe. Cerita orang yang tersakiti lebih dominan di jadikan sebagai lirik lagu didi kempot sehingga para pendengarnya mungkin merasa perasaan mereka dapat terwakili oleh lagu-lagunya," lanjutnya.

Informan diatas menerangkan kalau dirinya juga menyukai lagu Didi Kempot sejak kecil. Faktor historis budaya Jawa juga yang membuat Anin juga menyukai, walau ia tinggal di Jakarta. Bahkan, ia menilai bahwa lagunya sederhana, dan sesuai dengan kejadian sehari-hari. Ini menunjukkan bahwa, di tengah era industrialisasi informasi yang memunkinkan untuk mendapat informasi apapun dengan begitu cepatnya, lagu Didi Kempot seakan menembus batas sejarah dan waktu, dan bahkan umur masyarakat, membuat siapapun dapat terlena oleh lagu ini. Ditambah dengan pemanfaatan teknologi yang dikian pesat membuat lagu Didi Kempot nyata adanya sebagai budaya populer yang kian berkembang pesat.

"Saya tidak terlalu tau tentang cendol dawet dan bisa di bilang memang tidak tau soal itu. Tapi jika di kaitkan dengan didi kempot mungkin karna cendol itu mudah di dapat, di sukai semua kalangan dan rasanya enak. Mungkin dimaksudkan kalo lagu" didi kempot pun demikian... memang pada kenyataannya pun begitu, yg saya lihat dari anak kecil sampai orang dewasa menyukai lagu"nya dan memang jika kita dengarkan dengan baik lagu"didi kempot enak utk di dengarkan," kata Anin kepada penulis melalui media daring WhatsApp (27/10) 
Pada kesempatan ini, informan kedua (Anin) mengungkapkan bahwa ketika mendengar Cendol Dawet ia tidak mengetahui. Sama seperti informan pertama, bahwa Cendol Dawet memang tidak dipahami, namun secara implisit, menjadi semakin tertarik dengan semakin tren dan booming lagu Didi Kempot dengan Cendol Dawet.

Lebih lanjut, ini menunjukkan, bahwa makna terselubung yang ditampilakan oleh produsen jelas memikat publik. Dengan adanya kalimat Cendol Dawet, nyatanya membuat publik semakin tertarik dan tidak memperdulikan makna, melainkan semakin membuat publik tidak memiliki banyak pilihan ketika industri media menampilkan itu sebagai satu kesatuan untuk dikonsumsi publik.

Temuan Mariani (2016) dalam risetnya menjelaskan bahwa sejatinya pemanfaatan media dapat digunakan untuk membangun kesadaran akan kelas buruh. Namun sebaliknya, memalingkan kelas buruh dari kondisi-kondisi aktual yang memarginalkan mereka. Mariani (2016), menyoroti dampak yang begitu besar dari adanya media. Oleh karenanya, dalam kerangka diatas, sejujurnya dapat dipahami bahwa media menjadi alat penting untuk mengganggu emosi dan kemudian menemukan pasarnya (masyarakat). Perilaku tersebut, juga terihat dalam temuan ini bahwa Cendol Dawet dalam lagu Didi Kempot menjadi tren budaya populer kekinian.

Dari uraian diatas, agaknya dapat dimaknai bahwa (sesuatu) nilai/budaya tertentu tidak memandang bahwa itu apa nilainya, melainkan dipahami dan diterima
(Cendol Dawet dalam lagu Didi Kempot) sebagai wujud kesenangan, dan ekspresi hati. Akhirnya, secara tidak sadar masyarakat masuk dalam pusaran industri media. Sejalan dengan ini, juga ditemukan dalam penelitian yang dikembangkan Mariani (2016) bahwa buruh perempuan tidak benar-benar secara sadar dalam mengkonsumsi media. Konsumsi buruh perempuan terhadap media lebih menyerupai transaksi dimana buruh menukarkan waktu luangnya dengan kesenangan-kesenangan yang dikomodifikasi media untuk dapat mengurangi kepenatannya dalam berkerja.

Kemudian, ditambah dengan masyarakat Indonesia yang cenderung sangat konsumeris, akhirnya tindakan masyarakat menjadi dikontrol oleh budaya industri yang ia minati sebagai wujud kesenangan dan ekspresi hati. Dalam konteks ini, masyarakat modern kini seperti yang diungkap oleh Baudrillard (1983) (dalam Mariani 2016) bahwa dalam masyarakat postmodern, orang tidak merdeka mencipta obyek-obyek namun justru dikontrol oleh obyek-obyek itu dalam tindakan konsumsi. "Kita tidak lagi mengontrol obyek tetapi dikontrol olehnya, kita hidup sesuai iramanya, sesuai dengan siklus perputarannya yang tidak putus-putusnya". Dalam bahsa Mariani (2016), "kita tidak menguasai simbol, status, prestise lewat obyek-obyek konsumsi, kita justru terperangkap di dalam sistemnya."

Selanjutnya, dengan begitu, wujud kesenangan dan ekspresi hati itu menjadimenurut Horkheimer, menjadi sikap dimanipulasi oleh prasangka tertentu yang disebut dengan kesadaran semu yang 
digerakkan oleh modal (apa yang kelihatan objektif, tapi sesungguhnya semu), sehingga lanjut Horkheimer, dalam satu titik tertentu manusia modern akan hancur identitiasnya.

Pencarian identitias merupakan usaha manusia untuk menemukan kesejatian dirinya, menjadi otonom sama dengan menjadi diri sendiri. Namun, kenyataannya menunjukkan dalam usaha menemukan kesejatian itu, manusia justru kehilangan dirinya sendiri karena kebebasannya terkondisi dan diperalat oleh kekuatan diluar diri manusia, yang memanfaatkannya untuk kepentingan apa saja, yang dalam konteks ini media industri produsen Cendol Dawet sedang berada membangun dan mendominasi segmentasi publik, termasuk capaian diminati oleh generasi milenial di Indonesia.

Berdasarkan analisis tersebut, senada dengan pandangan Horkheimer bahwa manusia modern harus menggunakan kebebasannya secara bertanggungjawab. Dengan maksud lain, rasionalitas yang membebaskan manusia dari kekuasaan luar atas dirinya-meminjam istilah Horkheimer, rasionalitas emansipatif.

\subsection{False Needs Marcuse Lagu Didi Kempot}

Poespowardojo dan Seran (2016) menjelaskan, Adorno menilai masyarakat industri maju menciptakan kebutuhan palsu melalui media iklan yang mengerangkeng individu dalam sistem produksi dan konsumsi. Hal yang dinilai Adorno diatas ketika itu adalah iklan yang menjadi sorotan, namun secara umum industri media seperti musik, budaya.
Teori yang cukup terkenal ini, Marcuse mengatakan bahwa, manusia dalam masyarakat kapitalis yang telah maju adalah manusia yang tidak bebas, represif, dan bahwa manusia modern itu secara intelektual dan psikologis menjadi nyaman lewat ketergantungan secara psikologis pada persuasi masyarakat konsumeristik. Ketergantungan itu dinamakan desublimasi represif (repressive desublimation).

Merujuk konsep diatas, kebutuhan palsu (false needs) itu menjadi kentara adanya dengan adanya Cendol Dawet dalam lirik lagu Didi Kempot yang dinyanyikan Didi Kempot membuat perhatian dan kesenangan semua kalangan, termasuk generasi milenial. Hal ini dikarenakan konser-konser yang dibawakan oleh Didi Kempot dengan artistik lagu dan tambahan lirik Cendol Dawet nya.

Marcuse menerangkan konsep False Needs bahwa mengkonsumsi musik, budaya populer itu adalah kondisi yang dipilih dan menguntungan industri, dan itu bukanlah pilihan publik. Melainkan, pilihan industri. Pada titik tertentu, publik menjadi tidak otonom, dan pilihan-pilihan hak publik mengenai sesuatu seolah terbatas.

Dengan begitu, media yang menawarkan pilihan industri tersebut secara massif. Lalu, masyarakat modern, seperti yang diungkap Marcuse menjadi manusia berdimensi tunggal, bukan manusia multidimensi. Hal tersebut Marcuse tuliskan dalam tiga bukunya yang berjudul One Dimensional Man (1964), Eros and Civilization (1955), dan Counterrevolution and Revolt (1972). 
Didi Kempot dalam lagunya kini, membuat generasi milenial merasa begitu bahagia, dan senang karena ada Cendol Dawet dengan khas musik Jawa koplo. Padahal, jika disimak dengan seksama, lirik Cendol Dawet yang berada di selipan lirik lagu Didi Kempot tidak ada kaitannya. Artinya, tidak ada makna eksplisit Cendol Dawet dengan makna lagunya yang populer. Kesenangan generasi milenial ini disebabkan oleh lagu dan Cendol Dawet menghibur. Dengan begitu, industri budayasenada dengan Arybowo (2010), yaitu gerakan halus yang dapat mengubah pikiran, pandangan hidup, citarasa suatu bangsa.

Perilaku keranjingan terhadap budaya populer terjadi, menurut hasil penelitian Suparmi (2014) disebabkan oleh pengaruh pengaruh budaya yang menghibur, disenangi dan sifatnya massal. Terbentuknya perilaku seperti ini juga disebabkan oleh kesenangan remaja urban yang ditawarkan oleh media sosial. Terbentuknya perilaku seperti ini juga disebabkan oleh kesenangan remaja urban yang ditawarakan oleh media sosial.

Marcuse (1964) dalam bagian pertamanya yang ia beri judul "OneDimensional Society" menerangkan konsep false needs.

"Such needs have a societal content and function which are determined by external powers over which the individual has no control; the development and satisfaction of these needs is heteronomous. No matter how much such needs may have become the individual's own, reproduced and fortified by the conditions of his existence; no matter how much he identifies himself with them and finds himself in their satisfaction, they continue to be what they were from the beginning-products of a society whose dominant interest demands repression."

Produk budaya yang menjadi tren ini, sekali lagi, hemat peneliti, semacam 'ilusi' untuk terpenuhinya kepuasaan khalayak dalam menikmati lagu Didi Kempot dengan segala artistiknya (kebutuhan semu). Kondisi demikian, oleh Marcuse, kebutuhan itu memiliki konten dan fungsi sosial yang ditentukan oleh kekuatan eksternal yang tidak dapat dikontrol individu. Atas dasar diatas. Menyangkut media, dan produsen budaya industri; Didi Kempot hasilkan (produk lagu \& artistiknya) berdasar dari kultural masyarakat dan bentukan realitas produsen yang minat dominannya menuntut kesadaran semu.

Maka, dalam konteks inilah, fenomena tren budaya industri lagu Didi Kempot mengisyaratkan masyarakat berada dalam pusaran budaya industri seolah tidak memiliki otonomi untuk memilih karena sudah menjadi kebahagiaan kolektif.

Kemudian hal tersebut juga dipengaruhi oleh media yang mempublikasikannya dengan berbagai cara, seperti yang dilakukan oleh Didi Kempot melalui publikasi lagunya di YouTube, berita, media sosial Instagram (@sobatambyar sekaligus kru Didi Kempot) dengan membagikan info-info konser musik Didi Kempot, dan membuat fanspage komunitas Didi Kempot dengan sebutan Sobat Ambyar dari berbagai daerah; pulau Jawa yaitu diantaranya Sobat Ambyar Jakarta, Tangerang, Bekasi, Depok, Semarang, Salatiga, Pati, Ponorogo, Kebumen, Kediri, Boyolali, 
Cikarang, Bekasi, Malang, Grobogan, Klaten, Tegal, Nganjuk, Blora, Wonogiri, Purwodadi, Kudus, Magetan, Temanggung, Baturetno, Ngawi, Surabaya, Pemalang, Tulungagung, Cepu, Pekalongan, Solo Raya, Cilacap, Sukoharjo, Jepara, Cirebon, Banjarnegara, Sidoarjo, Purbalingga, Gunungkidul, Karawang. Kemudian, di Pulau Bali ada Sobat Ambyar Bali. Sementara itu, di wilayah Sumatera ada Sobat Ambyar Sumatera Utara, Riau. Sementara, di pulau Kalimantan yaitu Sobat Ambyar Balikpapan.

Jika ditinjau pada konsep false needs, akhirnya masyarakat mengkonsumsi lagu Didi Kempot dengan Cendol Dawet sebagai budaya populer dan pada satu kondisi tertentu secara tidak sadar mereka sedang dibatasi pada satu budaya tersebut — seolah tidak ada pilihan budaya lainnya.

Artinya, pada kondisi demikian, hal ini secara tidak sadar, masyarakat dikontrol, seolah tidak memiliki otonomi untuk memilih (industri budaya lainnya) karena sudah menjadi kebahagiaan kolektif (kebutuhan palsu).

Dampaknya pada realitas yakni, masyarakat dan kini generasi milenial yang notabene bukan orang yang budaya Jawa pun mengkonsumsi lagu Didi Kempot dengan Cendol Dawet nya. Akhirnya, industri budaya merekonstruksi itu dan menampilkannya melalui media sosial (sebagaimana yang telah diuraikan diatas)—sebagai upaya kesadaran semu berupa reproduksi budaya dengan sedemikian rupa sehingga dapat mengambil untung besar dari pasar.
Di sisi lain, Bagi Horkheimer dan Adorno, 'industri budaya' sama dengan 'antipencerahan'. Kalau proyek pencerahan adalah untuk membebaskan manusia dari mitos dan untuk menjamin kebebasan individu untuk berpikir, 'industri budaya' hanya membawa manusia pada penindasan dan dominasi. Mesin-mesin dominasi, yaitu modal dan teknologi, telah menghambat 'perkembangan individu yang otonom dan mandiri yang menilai dan memutuskan secara sadar untuk diri mereka sendiri.

Maka dari itu, Adorno pun (dalam Poespowardojo dan Seran 2016) melihat industri kebudayaan memanipulasi masyarakat melalui iklan dengan akibat menciptakan masyarakat yang pasif, karena kesenangan yang mudah diperoleh melalui konsumsi budaya populer. Dengan kritik Adorno kepada masyarakat modern bahwa masyarakat modern begitu pasif, mudah memperoleh kesenangan melalui konsumsi budaya populer-hal ini disebut kepuasan semu. Tidak ada kebebasan dirinya, menjadikan masyarakat semakin terbatas akan pilihan/selera atau dengan kata lain keinginannya. Budaya populer ini, tergambarkan senada dengan kondisi masyarakat Indonesia saat ini yang terpapar efek lagu Didi Kempot yang populer dengan Cendol Dawet. Cendol Dawet seolah sihir bagi siapapun dia, tidak mengenal ras, agama, termasuk generasi milenial.

Secara sederhana, fenomena pop culture Cendol Dawet dalam lagu Didi Kempot ini mengakibatkan menghalangi perkembangan kemandirian dari individuindividu yang bebas, dan seharusnya mampu 
menilai dan memutuskan sendiri secara sadar apa yang penting untuk diri mereka sendiri.

\subsection{Komodifikasi Konten Lagu Didi Kempot}

Kritik Adorno secara kuat, tanpa meminggarkan hal lain, nampaknya dipengaruhi oleh pemikran tentang musik. Ia memperoleh gelar doctor habilis pada tahun 1931 dengan karya yang berjudul Kierkegaard: Contruction of The Aesthetic (Poespowardojo dan Seran 2016).

Lebih lanjut, Adorno pernah mengkritik satu teks kontroversial yang berjudul On Jazz atau Uber Jazz. Baginya, jazz mengacu pada semua musik populer sebagai sebuah sistem yang dikontrol untuk meningkatkan komodifikasi melalui ekspresi artistik. Marcuse juga menggunakan contoh bagaimana Beethoven direduksi dari musik simfoni menjadi Muzak elevator. Penggambaran di atas adalah ungkapan Marcuse dalam Aesthetic Dimension (1978) yang menjelaskan fungsi kritis seni dan budaya, serta melihat penyerapan budaya ke dalam siklus komodifikasi dan hegemoni (Agger 2017, Poespowardojo dan Seran 2016).

Komodifikasi, menurut Mosco (2009) merupakan proses transformasi (mengubah) produk/jasa untuk dipasarkan dan memiliki nilai tambah untuk ditukarkan (dari nilai guna menjadi nilai tukar). Dalam artian, proses mengubah nilai guna menjadi nilai jual. Proses ini, dalam konteks ini, ketika fenomena tren lagu Didi Kempot ini diproduksi dan diviralkan secara terusmenerus, maka komodifikasi tercipta.
Komodifikasi konten merupakan transformasi pesan dari mulai dari bit data hingga sistem makna hingga termanifestasi produk yang dapat dipasarkan (Mosco 2009).

Dalam arti ini, relasi produser industri budaya, media, masyarakat, dan pasar menjadi hubungan integral yang tak terpisahkan dalam mewujudkan nilai tukar-pemenuhan kebutuhan masyarakat. Pada konteks ini, apa yang dinyatakan oleh Mosco (2009) menyoroti mengenai pentingnya peran proses komunikasi (makna) dan teknologi akan memperluas informasi tentang seluruh rangkaian produksi, distribusi, dan penjualan.

Dalam konteks ini, proses komodifikasi konten terjadi melalui ekspresi artistik dalam lagu Didi Kempot ini, ditambah dengan adanya artistik dalam lirik Cendol Dawet yang ditampilkan melalui kanal YouTube dengan monetisasi, barang dagangan serba Didi Kempot dijual melalui Instagram, dan juga banyaknya agenda konser eksklusif Didi Kempot seperti konser yang ada dalam program televisi, di undang dalam konserkonser, maupun dari event organizer.

Dari konteks diatas, Menurut Mosco (2009) dimaknai sebagai proses pengemasan melalui teknologi digitalisasi yang memperluas komodifikasi konten komunikasi dengan berbagai peluang untuk mengukur dan memantau, mengemas dan mengemas ulang, informasi dan hiburan. Pengemasan hiburan dengan bantuan teknologi (digitalisasi) berupa pemanfaatan fitur kanal YouTube, Instagram Didi Kempot dan fanspage nya membuat proses komodifikasi menjadi semakin terjaga - tidak menutup kemungkinkan pada 
proses mistifikasi melalui slogan "sakit hati mending dijogeti" oleh Didi Kempot.

Proses komodifikasi konten ini juga pernah diteliti sebelumnya oleh para pemikir komunikasi. (Handoyo 2019, Telling 2012, Khadavi 2014, Ulya 2019, Arviani 2013, Iqbal 2019, Enga 2016, Lase 2014, Musthofa 2012, Perdana 2017, Surahman, Annisarizki, dan Rully 2019).

Mistifikasi juga ditemukan oleh beberapa peneliti, seperti temuan Ulya (2019) menunjukkan adanya mistifikasi berupa slogan YouTube, "Broadcast Yourself", secara tidak sadar, mengajak untuk menjadi bagian dari YouTube, membuat konten dan melakukan monetisasi. Hal ini juga ditemukan, dalam penelitian Iqbal (2019) bahwa terdapat komodifikasi konten akun YouTube Klepon Parot yang mana ketika YouTube memberikan akses (izin) untuk memonetisasi kontennya; yang awalnya konten tersebut untuk sosialisasi semata, kini kontennya mendapat penghasilan (gaji).

Maka, dalam konteks ini, lagu Didi Kempot diterima dan menjadi terpenuhi kebutuhan masyarakat. Namun, dapat dipahami bahwa secara tidak sadar, masyarakat dikontrol alih-alih sebagai dalam rangka memenuhi kebutuhan "hiburan" semata, dibalik itu masyarakat seolah tidak memiliki otonomi untuk memilih (industri budaya lainnya) karena sudah menjadi kebahagiaan kolektif (kebutuhan palsu).

Proses diatas, komodifikasi konten, dalam penggambaran Mosco (2009) berjalan dimulai saat pelaku media (penyanyi dan tim media Didi Kempot) mengubah pesan melalui teknologi yang ada menuju sistem interpretasi yang bermakna, sehingga menjadi pesan yang begitu marketable. Dalam hal ini, terdapat sebuah pemanfaatan barang dan jasa yang dari nilai gunanya dikomodifikasikan menjadi komoditas yang memiliki orientasi pada nilai tukarnya ketika di pasar.

Kemudian, disisi lainnya, artistik lirik Cendol Dawet itu menjadi populer (familiar). Artinya, industri budaya telah menyatukan 'yang lama' dengan 'yang familiar' ke dalam satu kualitas baru berupa produk industri. Hal itu mengarah pada komodifikasi. Proses komodifikasi berhubungan dengan produk (Manggaga 2018). Bentuknya atau produk industri dalam konteks ini yakni, lagu Didi Kempot dengan artistik lirik Cendol Dawet, ditambah aransemen musik khas Jawa koplo.

Menurut Adorno (dalam Marris dan Tornhman 1997) bahwa budaya yang diproduksi secara massif dan standar sesungguhnya produk dari industri semata, bukan berasal dari ekspresi kultural masyarakat. Pernyataan diatas, dalam konteks ini menggambarkan tren budaya industri Didi Kempot - produk industri budaya yang tadinya hiburan lagu Didi Kempot saja, saat ini menjadi tren lagu Didi Kempot, kemudian ditambah artistik lirik Cendol Dawet, dan aransemen Jawa koplo, serta dipublikasikan dalam media, dan melakukan penjualanpenjualan merchandise serba Didi Kempot, yang gambarnya diambil dari lagu, foto Didi Kempot, maupun kutipan dari Didi Kempot sendiri.

Dengan begitu, tren musik Didi Kempot sebagai wujud produksi budaya baru 
ini, merupakan potensi komodifikasi yang kuat. Musik pop, dapat menunjukkan fitur komodifikasi, reifikasi, dan standardisasi, musik pop juga dapat sama mengekspresikan emosi kegembiraan, juga kesakitan, kemarahan, pemberontakan, seksualitas, dan lain-lain (Adorno 1991).

Dalam kerangka demikian, tren lagu Didi Kempot yang kini familiar diminati memang diciptakan untuk kepentingan konsumsi massa yang dalam banyak hal menentukan asal-muasal konsumsi tersebut sehingga diciptakan dengan perencanaan yang strategis dalam hitungan bisnis.

Oleh sebab itu, massa bukanlah penentu utama, melainkan adalah sekunder. Senada dalam asumsi budaya industri yakni massa adalah objek kalkulasi, sebuah aksesori dari kerja mesin, serta bukan sebuah raja, namun sekadar objek yang dapat dieksploitasi untuk keperluan komersil produsen.

Produk industri budaya baru ini (tren lagu Didi Kempot \& artistik dalam lirik Cendol Dawet nya) menghasilkan keuntungan secara tidak langsung, melampaui dan di atas esensi sebenarnya. Hemat penulis, sesuatu yang baru di produksi ulang tersebut dengan segala kemungkinannya sebagai wujud bagian industri budaya merupakan keutamaan dari keefektifan yang sudah dikalkulasikan oleh prosedurnya. Dalam artian, industri budaya telah mempunyai sistem produksi dan distribusi yang dirancang sedemikian rupa sehingga akan muncul seolah 'ilusi' yang memperdaya pilihan masyarakat, sehingga akhirnya, menghasilkan keuntungan, yang sebenarnya melebihi makna esensi dari produk yang dikeluarkan.

Dengan demikian, otonomi karya seni-keterbebasan dari segala pengaruh dan bisa mencerahkan - secara bertendensi dihapuskan oleh industri budaya, dengan atau tanpa kebijakan yang disadari oleh pemegang kendali. Demikian halnya pada kalimat Cendol Dawet yang kemudian diproduksi, kemudian mengaransemen Jawa koplo lalu disiarkan dalam konser, dan media sosial, bahkan tidak sedikit para fans akhirnya membuat media sosial memberikan informasi pada publik mengenai jadwa-jadwal konser Didi Kempot, kemudian tidak sedikit merchandise apapun tentang Didi Kempot, seperti kaos Sobat Ambyar, konstruksi gambar-gambar patah hati yang mengutip dalam lagu dan kalimat langsung Didi Kempot.

Selain itu, juga dengan viralnya videovideo yang mengekspresikan hati publik ketika menonton dan mendengarkan musik Didi Kempot saat konser Didi Kempot berlangsung, dan tidak jarang pula mengunggah dan menyebarluaskan kembali video konser musik Didi Kempot dengan Cendol Dawet nya. Semua ini terekam bahwa Cendol Dawet dalam lagu Didi Kempot menjadi sebuah komoditas yang unik, kreatif, menarik, bagi segenap masyarakat.

Ini menadakan bahwa Cendol Dawet sebagai sebuah tindakan kreatif untuk mendatang keuntungan sebagai asal-muasal keberadaanya. Ini yang mengarah pada komiditas; sebuah komoditas dari awal sampai akhir, dari proses produksi, distribusi, penjualan. Secara eksplisit, keuntungan secara 
finansial menjadi tujuan dalam ideologinya, dan menjadi wilayah kuat-independen dari kekuatan penjualan komoditas kultural yang harus diperoleh dnegan secara cara. Maka, secara tersirat Adorno juga mengatakan industri budaya semacam ini dianggap sematamata sebagai nothing yang hanya menjadi bernilai karena sistem promosi-distribusi di atas segala-galanya.

Akhirnya, hemat penulis, massa sama sekali tak berdaya dan menjadi kompromistis terhadap produk industri budaya lagu Didi Kempot dan lirik artistik Cendol Dawet. Budaya massa ini membuat masyarakat semacam mengikuti begitu saja tuntutan konsumeristik. Tren budaya ini, pada akhirnya, secara tidak langsung, membuat kondisi kepuasan semu bagi individu dan masyarakat yang disebabkan tidak adanya kebebasan untuk memilih (tidak otonom), dan kebahagiaan sejati.

Kesemua itu, seperti yang diungkap oleh Marcuse dalam Eros and Civilization (1955) dan Essay on Liberation (1969) bahwa kemajuan teknologi menyiapkan jalan bagi pembebasan dari kekurangan, yang kemudian menempatkan batas objektif atas pembebasan manusia. Teringat ungkapan Marx, serupa dengan itu sebagai "jam kerja wajib buruh" harus dikurangi kalau orang ingin merasakan pembebasan sejati (Agger 2017).

\section{Simpulan dan Saran}

Berdasarkan temuan hasil penelitian, peneliti dapat menyimpulkan bahwa terdapat dorongan dan motivasi masyarakat, termasuk generasi milenial untuk menerima (menyukai) lagu Didi Kempot sebagai bagian dari upaya kesenangan dan manifestasi ekspresi hati saja tanpa harus tahu makna (asali) isi pesan lagu tersebut.

Dalam kondisi demikian, secara tidak sadar, terdapat komodifikasi konten lagu Didi Kempot ditambah lirik Cendol Dawet yang ditampilkan melalui kanal YouTube dengan monetisasi, barang dagangan serba Didi Kempot dijual melalui Instagram, dan juga banyaknya agenda konser eksklusif Didi Kempot seperti konser yang ada dalam program Televisi, di undang dalam konserkonser, maupun dari event organizer.

Maka, dalam konteks ini, dapat dipahami bahwa secara tidak sadar, masyarakat dikontrol, lalu (seolah) tidak otonom sebagai masyarakat yang memiliki hakikat untuk memilih (industri budaya lainnya). Sebab, hal tersebut sudah menjadi kebahagiaan kolektif yang bersifat semu (kebutuhan palsu).

Kemudian, saran untuk penelitian selanjutnya yakni diharapkan untuk melakukan analisis dengan metode campuran (mix methods), yakni secara kuantitatif dapat meneliti persepsi masyarakat akan tren budaya lagu Didi Kempot ini, dan secara kualitatif, dapat ditelusuri makna, pengalaman penyanyinya, penggemar dalam komunitasnya, dan penggemar non komunitas (masyarakat umum) sebagai bagian untuk melihat tren lagu ini lebih mendalam melalui masyarakat secara mendalam.

\section{Daftar Pustaka}

Adorno, Theodor W. 1991. The Culture Industry: Selected Essays on Mass 
Culture. London and New York: Routledge.

Agger, Ben. 2017. Teori Sosial Kritis: Kritik, Penerapan Dan Implikasinya. Bantul: Kreasi Wacana.

Arybowo, Sutamat. 2010. "Kajian Budaya dalam Perspektif Filosofi." Jurnal Masyarakat \& Budaya 12 (2).

Arviani, Heidy. 2013. "Budaya Global dalam Industri Budaya: Tinjauan Madzhab Frankfurt Terhadap Iklan, Pop Culture, dan Industri Hiburan." GLOBAL \& POLICY JOURNAL OF INTERNATIONAL RELATIONS, 1 (2).

Bhojanna, U. 2012. Research Methodology. New Delhi: Excel Books Private Limited.

Enga, Anastasia H.P. 2016. "Komodifikasi Pernikahan "Menuju Janji Suci" di Trans TV." Interaksi: Jurnal Ilmu Komunikasi 5 (2) : 177-186. https://doi.org/10.14710/interaksi.5.2.177 $-186$.

Ernungtyas, Niken Febrina, Ratih Puspita, Sri Indah Suryaningsih, Yesi Rizki Amelia, Lamini, dan Yana Hendarrita. 2016. "Youth Culture Dan Gaya Busana: Hiper-Realitas Pekerja Muda Perempuan Terhadap Produk Fashion Bermerek Di Jakarta.” Jurnal Nomosleca 2 (1). https://doi.org/https://doi.org/10.26905/n omosleca.v2i1.379.

Handoyo, Ardina Indraswati. 2019. "Pengungkapan dan Komodifikasi Privasi dan Selebriti Indonesia Melalui Vlog (Studi Analisis pada Kanal YouTube RANS Entertainment)." Universitas Airlangga.

Iqbal, Rizkianur. 2019. "Komodifikasi Video Game di Sosial Media (Studi Kasus Video Game Resident Evil VII: Biohazard)." Skripsi. Ilmu Komunikasi Universitas Ahmad Dahlan.

Khadavi, M. Jadid. 2014. "Dekonstruksi Musik POP Indonesia dalam Perspektif Industri Budaya." Jurnal Humanity,
Universitas Muhammadiyah Malang 9 (2).

http://ejournal.umm.ac.id/index.php/hum anity/article/view/2392.

Lase, Formas Juitan. 2014. "Komodifikasi Konten Humor dalam Program Yuk Keep Smile di Trans TV." Jurnal Sociae Polites 15 (2).

http://ejournal.uki.ac.id/index.php/sp/arti cle/view/456

Manggaga, Indah Pratiwi. 2018. "Komodifikasi Konten Televisi Dalam Perspektif Ekonomi Politik Media." Jurnal Dakwah Tabligh 19 (2): 257-76. http://journal.uinalauddin.ac.id/index.php/tabligh/article/v iew/7478/6116.

Marcuse, Herbert. 1964. One-Dimensional Man. 2nd ed. London and New York: Routledge \& Kegan Paul.

Mariani, Ana. 2016. "Mengungkap Budaya Konsumsi Media Buruh Perempuan lewat Perspektif Cultural Studies (Studi Etnografi pada Buruh Industri \& Rumah Tangga di Malang).” Jurnal Nomosleca 2 (1). http://jurnal.unmer.ac.id/index.php/n/arti cle/view/345.

Marris, Paul dan Tornhman, Sue. 1997. Media Studies: A Reader. Edinburgh: Edinburgh University Press

Mosco, Vincent. 2009. The Political Economy of Communication. California: SAGE Publication, Inc.

Musthofa, As'ad. 2012. "Komodifikasi Kemiskinan Oleh Media Televisi." Jurnal MAKNA 3 (1): 1-14.

https://doi.org/http://dx.doi.org/10.30659 /jikm.3.1.1-14.

Neuman, W. Lawrence. 2014. Social Research Methods: Qualitative and Quantitative Approaches Seventh Edition. Harlow, Essex: Pearson Education Limited.

Perdana, Dionni Ditya. 2017. "Komodifikasi Dalam Tayangan Televisi (Kajian Terhadap Program Indonesian Idol 
2014)." Jurnal Professional FIS UNIVED 4 (1): 12-21.

https://doi.org/10.29313/mimbar.v31i1.1 262.

Poespowardojo, T.M. Soerjanto, and Alexander Seran. 2016. Diskursus TeoriTeori Kritis: Kritik Atas Kapitalisme Klasik, Modern, Dan Kontemporer. Jakarta: Kompas Media Nusantara.

Suparmi, Tiara Arum. 2014. "Perilaku Remaja Urban terhadap Pop Culture (Studi Deskriptif Perilaku Keranjingan Remaja Urban di Surabaya)." Journal Unair 3 (2): 1-19.

http://journal.unair.ac.id/Kmnts@ perilak u-remaja-urban-terhadap-pop-culture(studi-deskriptif-perilaku-keranjinganremaja-urban-di-surabaya)-article-6558media-135-category-8.html.

Surahman, Sigit, Annisarizki, dan Rully. 2019. "Komodifikasi Konten, Khalayak, dan Pekerja pada Akun Instagram @salman_al_jugjawy.” Nyimak(Journal of Communication) 3 (1): 15. https://doi.org/10.31000/nyimak.v3i1.12 08 .

Telling, Ronaldy Zefanya. 2012. "Komodifikasi "Kegilaan" Toni Blank dalam Social Media (Analisis Wacana Kritis terhadap "Kegilaan" Toni Blank pada Toni Blank Show di YouTube)." Skripsi. Universitas Indonesia.

Ulya, Himmatul. 2019. "Komodifikasi Pekerja Pada Youtuber Pemula Dan Underrated." Interaksi: Jurnal Ilmu Komunikasi 8 (2): $1-12$. https://doi.org/https://doi.org/10.14710/in teraksi.8.2.1-12.

Internet:

Kompas. Sobat Ambyar Dan Sihir Didi Kempot (20 Oktober 2019). diakses tanggal 25 Oktober 2019, https://entertainment.kompas.com/jeo/so bat-ambyar-dan-sihir-didi-kempot

Tribunews.com. Trending Topic Didi Kempot. (12 Juni 2019). diakses tanggal 25 November 2019. https://www.tribunnews.com/seleb/2019/ 06/12/berawal-pengamen-hinggasejarah-nama-kempot-ini-5-fakta-didikempot-the-godfather-of-broken-heart

YouTube. Didi Kempot - Banyu Langit [OFFICIAL] (23 November 2018). diakses tanggal 10 Mei 2020. https://www.youtube.com/watch?v=20_ CyA4CCTs 